\title{
Occupational stress, job satisfaction, and intent to leave: nurses working on front lines during COVID-19 pandemic in Zagazig City, Egypt
}

\author{
Randa M. Said ${ }^{1} \cdot$ Dalia A. El-Shafei ${ }^{2}$ (D) \\ Received: 1 July 2020 / Accepted: 12 October 2020 / Published online: 17 October 2020 \\ (C) Springer-Verlag GmbH Germany, part of Springer Nature 2020
}

\begin{abstract}
During epidemics, the medical working environment is highly stressful especially for the nurses. The purpose of this study was to assess occupational stress, job satisfaction, and intent to leave among nurses dealing with suspected COVID-19 patients. A comparative cross-sectional study was conducted among 210 nurses from Zagazig Fever Hospital (ZFH) which is one of COVID-19 Triage Hospitals (Group I) versus 210 nurses from Zagazig General Hospital (ZGH) (Group II) which is neither triage nor isolation hospital; dealing only with suspected COVID-19 patients in emergency at Sharkia Governorate, Egypt, from 10th to 24th of April 2020. Assessment was done through online questionnaire formed of the Expanded Nursing Stress Scale, the McCloskey/Mueller Satisfaction Scale, and questionnaire assessing specific COVID-19-associated stressors and nurses' intent to leave. Three quarters of nurses (75.2\%) in ZFH had high stress level versus 60.5\% in ZGH. Workload (98.6\%), dealing with death and dying (96.7\%), personal demands and fears (95.7\%), employing strict biosecurity measures (95.2\%), and stigma (90.5\%) represented the highest priority stressors in ZFH, while exposure to infection risk (97.6\%) was the stressor of highest priority among ZGH according to Pareto analysis. More than half of nurses (51.0\%) in ZFH reported low satisfaction level versus $41.9 \%$ in ZGH. Only $4.8 \%$ of nurses in ZFH definitely had no intent to leave their present job. Type of hospital and its related workload were the most significant predictor of all the studied outcomes.
\end{abstract}

Keywords Occupational stress $\cdot$ Job satisfaction $\cdot$ Intent to leave $\cdot$ Nurses $\cdot$ Front-lines $\cdot$ Triage hospital $\cdot$ General hospital COVID-19 pandemic $\cdot$ Egypt $\cdot$ Pareto analysis

\section{Introduction}

Healthcare workers (HCWs) represent the defense front lines who take care of patients every time a pandemic or an epidemic arises, such as measles, scarlet fever, HIV/AIDS, SARS, H5N1, H1N1, Ebola, MERS, or the flu of 2013 (Jun

Responsible editor: Philippe Garrigues

Electronic supplementary material The online version of this article (https://doi.org/10.1007/s11356-020-11235-8) contains supplementary material, which is available to authorized users.

Dalia A. El-Shafei

d_elshaf3y_mony@hotmail.com

1 Department of Family Medicine, Faculty of Medicine, Zagazig University, Zagazig, Egypt

2 Department of Community, Environmental and Occupational Medicine, Faculty of Medicine, Zagazig University, Zagazig, Egypt et al. 2020). The newly emerging Coronavirus Disease 2019 (COVID-19) pandemic was first identified in Wuhan, China, and now spread worldwide. The combination of stress and possible exposure makes HCWs highly susceptible for acquiring COVID-19 and potentially transmitting it to others (Neto et al. 2020).

To efficiently stop the spread of COVID-19 infection in Egypt, General Hospitals have designated COVID isolation areas inside them for managing emergency suspected COVID-19 cases and referring other nonemergency cases to Fever or Chest Hospitals which act as Triage Hospitals receiving all suspected COVID-19 cases either referred from General Hospitals or referred by hotline or walk-in patients. Nurses working in COVID isolation areas either in Triage Hospitals or General Hospitals together with other health team members represent the defense frontline (FL) against COVID-19 (Ministry of Health and Population 2020). 
Occupational stress is a fast-growing cause of work-related diseases and injury; specifically among HCWs (Hassan et al. 2020). Occupational stress associated with COVID-19 is an essential indicator of mental illness as it can lead to anxiety and depression in the confrontation of the co-occurrence of countless deaths, and long work shifts with the most diverse unknowns and demands. During the global response to the epidemic, HCWs are undoubtedly needed, but they represent one of the most vulnerable individuals in terms of acquiring the highly contagious disease. Lots of HCWs serving on the front lines of the COVID-19 pandemic have become infected and more have been in quarantine after exposure (Neto et al. 2020). Keeping the health of nurses is of paramount importance in managing infectious diseases as they have always played an essential role in prevention and control during epidemics (Mo et al. 2020).

Occupational stress and job satisfaction are essential factors influencing workforce productivity. Preserving high level of job satisfaction among HCWs especially nurses is critical for achieving the appropriate high quality medical service (Kabbash et al. 2020; Semachew et al. 2017). There is overwhelming evidence that current trends in working environment may have adverse effects on job satisfaction. Job satisfaction is the affective orientation that a worker has towards his/her work which consists of two facets: positive affectivity and negative affectivity. Positive affectivity is represented by high energy, enthusiasm, and enjoyable involvement while negative affectivity is indicated by distress, un-enjoyable involvement, and edginess. Occupational stress plays a vital role in job satisfaction; if it acts as a motivator, it will contribute to creativity and satisfaction and further will remove boredom, and if it acts as a negative factor, it will lead to aggression and low job satisfaction. On the other hand, job satisfaction may protect workers from stressors and act as a regulating factor for stress (Hoboubi et al. 2017).

Occupational stress has substantial direct and indirect effects on intention to leave the current organization and intention to leave the profession in the future. It mainly exerts its indirect effects through job satisfaction, depressed mood and stress adaptation. Intention to leave the current organization usually precedes intention to leave the profession. Policy makers should put intention to leave reduction strategies among nurses that should concentrate on creating a less stressful work environment, increasing job satisfaction and stress adaptation, and decreasing depressed mood concomitantly (Lo et al. 2018).

At present, studies on the COVID-19 pandemic mostly concentrated on epidemiological investigation, prevention and control, diagnosis, and treatment. Fewer studies have investigated the mental health and the working environment of HCWs during the COVID-19 pandemic (Mo et al. 2020). The purpose of the present study was to compare occupational stress, job satisfaction, and intent to leave among nurses dealing with suspected COVID-19 patients in triage hospitals versus those working in general hospitals which were neither triage nor isolation hospitals and dealing only with suspected COVID-19 patients in emergency where its role is stabilization of patients then referral to triage hospitals. This comparison would be useful to prioritize occupational stressors, identify degree of satisfaction, and intent to leave among both groups.

\section{Materials and methods}

A comparative cross-sectional study was conducted among nurses working in Zagazig Fever Hospital (ZFH) which is one of COVID-19 Triage Hospitals (Group I) versus those working in Zagazig General Hospital (ZGH) (Group II) which is neither triage nor isolation hospital and dealing only with suspected COVID-19 patients in emergency at Zagazig City, Sharkia Governorate, Egypt, from 10th to 24th of April 2020.

\section{Study population}

\section{Determination of sample size and sampling technique}

The sample size was calculated using Epi-Info version 6 statistical packages depending on the following data; confidence interval $95 \%$, power of test $80 \%$, ratio between two groups $1: 1$, the prevalence of work related stress among ZFH Group; $75 \%$ from pilot study and its prevalence among ZGH Group; and $62 \%$ from previous study (Kamal et al. 2005). So, the calculated sample size was 402 subjects divided into 201 subjects for each group. The study was conducted in two hospitals which had an adequate number of nurses during the study period. Zagazig Fever Hospital was selected from COVID Triage Hospitals in Sharkia Governorate as it accommodated 275 nurses and 119 beds while Zagazig General Hospital was selected from General hospitals in Sharkia Governorate as it accommodated 315 nurses and 135 beds.

Due to the fact that the study was conducted during the COVID-19 pandemic, the current isolation policy calls for reduced face-to-face contact and avoidance of large gatherings. Therefore, the authors decided to collect the data online. The nurses in each hospital already shared in online work groups on "WhatsApp" and "Facebook." The researcher communicated with the admins of these groups to get permission to share the online questionnaire through these groups. Questionnaire was structured by Google Form App then posted/reposted through nurses groups. The reception of the filled questionnaires had stopped when the sample size had achieved. The final sample size was 420 subjects divided equally between two groups.

Inclusion criteria included all on-job nurses that consented to participate in the study and filled in the online 
questionnaire. Exclusion criteria included (i) pregnant women and (ii) nurses who were on permanent extended leave exceeding 6 weeks duration during the time of the study.

The pilot study was done through an online questionnaire on $10 \%$ of the sample (40 nurses) working in Zagazig Chest Hospital which is one of COVID-19 Triage Hospitals during March 2020 to test the response to different items of the questionnaires, to test the feasibility of the study, and to test the questionnaire with the most appropriate terms. The results of the pilot were not included in the results of the study. According to the result of the pilot study, the questionnaire was assessed and minor modification was done.

\section{Data collection tools}

An online questionnaire was used which consisted of the following parts:

Part I: A brief introduction on the background, objective, procedures, voluntary nature of participation, declarations of anonymity and confidentiality, and exclusion criteria.

Part II: Socio-demographic characteristics and occupational history: Age, sex, marital state, education, years of experience, work hours per week, and night duties per week.

Part III: The Expanded Nursing Stress Scale (ENSS) was adapted from French et al. 2000. It is a valid and reliable tool targeting nursing stress. It contains 57 items on a five-point Likert scale with $0=$ never exposed, $1=$ never stressful, 2 = occasionally stressful, 3 = frequently stressful, and $4=$ extremely stressful. The items are grouped into nine subscales: (1) dealing with the death and dying (7 items, minimum score $=0$, maximum score $=28),(2)$ conflicts with physicians ( 5 items, $\min$. score $=0$, $\max$. score $=20)$, (3) inadequate emotional preparation (3 items, min. score $=0$, $\max$. score $=12$ ), (4) problems relating to peers (6 items, $\min$. score $=0$, $\max$. score $=24$ ), (5) problems relating to supervisors ( 7 items, $\min$. score $=$ 0 , max. score $=28),(6)$ workload $(9$ items, $\min$. score $=$ 0 , max. score $=36)$, (7) uncertainty concerning treatment (9 items, $\min$. score $=0$, max. score $=36$ ), (8) unreasonable demands of patients and their families ( 8 items, min. score $=0$, max. score $=32$ ), and (9) experience of being discriminated (3 items, $\min$. score $=0$, max. score $=12$ ). For each subscale, the participant's responses on each item are scored and summed to obtain a total score with higher scores indicate higher stress levels. The level of stress was calculated by summing the total score of all subscales, and was classified as follows: low with total score $\leq 76$, moderate 77-152, and high 153-228. It was modified by asking the participants to indicate how stressful each situation they have encountered in their present work setting during COVID-19 pandemic then translated into Arabic and validated through a back translation technique and pilot testing.

Part IV: Specific COVID-19 stressors derived and modified from US National Center for Posttraumatic Stress Disorder 2020 and "MERS-CoV staff questionnaire" of Khalid et al. 2016. It was developed in Arabic language and consisted of 19 items on 5-point Likert scale with $0=$ never exposed, $1=$ never stressful, 2 = occasionally stressful, 3 = frequently stressful, and $4=$ extremely stressful. The items are grouped into four subscales: (1) need to employ strict biosecurity measures (4 items, min. score $=0$, max. score $=16),(2)$ exposure to infection risk (6 items min. score $=0$, max. score $=24$ ), (3) personal demands and fears $(7$ items, $\min$. score $=0, \max$. score $=$ 28), and (4) stigma (2 items min. score $=0$, max. score $=$ 8). For each subscale, the participant's responses on each item are scored and summed to obtain a total score with higher scores indicate higher stress levels. The level of specific COVID-19-associated stress was calculated by summing the total score of all subscales, and was classified as follows: low with total score $\leq 25$, moderate 26 50, and high 51-76. Reliability test was done whereas Cronbach's Alpha equals 0.87 .

Part V: The McCloskey/Mueller Satisfaction Scale (MMSS) is one of the most widely used, valid, and reliable scales for measuring job satisfaction among nurses. It is a 31 -item on 5-point Likert scale with $1=$ very dissatisfied, $2=$ moderately dissatisfied, $3=$ neither satisfied nor dissatisfied, $4=$ moderately satisfied, and $5=$ very satisfied (Mueller and McCloskey 1990). The items are grouped into eight subscales: (1) extrinsic rewards (3 items, min. score $=1$, max. score $=15)$, (2) family and work balance ( 3 items, $\min$. score $=1$, $\max$. score $=15$ ), (3) professional opportunities ( 4 items, min. score $=1$, max. score $=20),(4)$ work control and responsibility $(5$ items, min. score $=1$, max. score $=25),(5)$ scheduling $(6$ items, min. score $=1$, max. score $=30),(6)$ coworkers $(2$ items, min. Score $=1$, $\max$. Score $=10)$, 7) interaction opportunities (4 items, $\min$. score $=1$, $\max$. score $=20$ ), and (8) praise and recognition (4 items, min. score $=1$, max. score $=20$ ) (Tourangeau et al. 2006). The mean score per subscale and for the entire questionnaire were calculated with higher scores which indicate higher satisfaction levels. The level of job satisfaction was also calculated by summing the total score of all subscales, and was classified as follows: low with total score $\leq 52$, moderate 53-104, and high 105-155. It was translated into Arabic then validated through a back translation technique and pilot testing.

Part VI: Nurses' intent to leave: The item that measured nurses' intent to leave asked the respondents to rate their feeling about their future work based on dichotomous 
responses (yes/no) to the survey question: "If possible, would you leave your current hospital within the next year as a result of job dissatisfaction?" This question was followed-up with the question, (only used in the descriptive analysis): "If yes, what do you intend to leave?" with the response options: "the current position"; "the current organization"; "the field of nursing" (Lagerlund et al. 2015).

\section{Statistical analysis}

The collected data were statistically analyzed using SPSS program (Statistical Package for Social Science) version 16.0. Chi-square test $\left(\chi^{2}\right)$ was carried out for comparing the qualitative data. Quantitative data were compared using Student's $t$ test. Binary logistic regression analysis was conducted to identify the predictors of each studied outcome. The test results were considered significant when $p$ value $<0.05$. Charts were drawn using Excel program. To draw Pareto chart, the following were done: (1) each subscale in ENSS and specific COVID-19-associated stressors by itself is basically a workrelated stressor and considered extremely stressful if achieved $75 \%-100 \%$ of subscale total score, (2) the frequency of each extremely stressful stressor was calculated, (3) after descending ranking of the different stressors, the cumulative percentage was calculated, and (4) the level of $80 \%$ cumulative percentage was taken as the cutoff point that identifies the corresponding factors related to COVID-19-associated stress.

\section{Results}

A total number of 420 nurses were included, 210 working in Zagazig Fever Hospital (ZFH Group) and 210 in Zagazig General Hospital (ZGH Group). The mean age of ZFH Group was $24.22 \pm 5.16$ which was significantly lower than $26.09 \pm 4.53$ for ZGH Group. The majority of the participants in both groups $(85.2 \%$ and $78.6 \%$, respectively) were females. The majority of ZFH Group (60.0\%) were single compared with $(49.5 \%)$ in ZGH Group with a statistically significant difference. Concerning occupational history, ZGH Group tended to have significantly higher work experience of $11.39 \pm 3.96$ years compared with $9.45 \pm 2.24$ years for $\mathrm{ZFH}$ Group. Regarding work hours per week, ZFH Group tended to have significantly longer work hours $(89.5 \%)$ compared with (60.0\%) of ZGH Group. In ZFH Group, only $11.9 \%$ did not have night shift work compared with $19.5 \%$ in ZGH Group. Difference in number of night shifts was significantly higher among ZFH Group than ZGH Group (Table 1).

Regarding occupational stress, it was significantly higher among ZFH Group (193.55 \pm 44.94$)$ than ZGH Group $(157.58 \pm 39.97)$ with the percent of participants who reported
Table 1 Socio-demographic characteristics and occupational history among both studied groups

\begin{tabular}{|c|c|c|c|}
\hline Items & $\begin{array}{l}\text { ZFH group } \\
N=210 \\
\text { No. }(\%)\end{array}$ & $\begin{array}{l}\text { ZGH group } \\
N=210 \\
\text { No. }(\%)\end{array}$ & $p$ value \\
\hline \multicolumn{4}{|l|}{ Age (years): } \\
\hline $20-39$ & $126(60.0)$ & $98(46.7)$ & \multirow[b]{3}{*}{$0.003 * *$} \\
\hline $40-59$ & $84(40.0)$ & $112(53.3)$ & \\
\hline $\begin{array}{l}\text { Mean } \pm \text { SD } \\
\text { Range }\end{array}$ & $\begin{array}{l}24.22 \pm 5.16 \\
19.0-45.0\end{array}$ & $\begin{array}{l}26.09 \pm 4.53 \\
20.0-48.0\end{array}$ & \\
\hline \multicolumn{4}{|l|}{ Sex: } \\
\hline $\begin{array}{l}\text { Male } \\
\text { Female }\end{array}$ & $\begin{array}{l}31(14.8) \\
179(85.2)\end{array}$ & $\begin{array}{l}45(21.4) \\
165(78.6)\end{array}$ & 0.076 \\
\hline \multicolumn{4}{|l|}{ Marital status: } \\
\hline $\begin{array}{l}\text { Un-married }{ }^{\#} \\
\text { Married }\end{array}$ & $\begin{array}{l}126(60.0) \\
84(40.0)\end{array}$ & $\begin{array}{l}104(49.5) \\
106(50.5)\end{array}$ & $0.031 *$ \\
\hline \multicolumn{4}{|l|}{ Education: } \\
\hline $\begin{array}{l}\text { School of nursing } \\
\text { Nursing institute } \\
\text { Faculty of nursing }\end{array}$ & $\begin{array}{l}65(30.9) \\
72(34.3) \\
73(34.8)\end{array}$ & $\begin{array}{l}79(37.6) \\
50(23.8) \\
81(38.6)\end{array}$ & 0.057 \\
\hline \multicolumn{4}{|l|}{ Years of experience } \\
\hline $\begin{array}{l}\text { Mean } \pm S D \\
\text { Range }\end{array}$ & $\begin{array}{l}9.45 \pm 2.24 \\
1.0-24.0\end{array}$ & $\begin{array}{l}11.39 \pm 3.96 \\
1.0-27.0\end{array}$ & $<0.0001 *$ \\
\hline \multicolumn{4}{|l|}{ Work hours/week } \\
\hline $\begin{array}{l}40 \mathrm{~h} \\
>40-60 \mathrm{~h}\end{array}$ & $\begin{array}{l}22(10.5) \\
188(89.5)\end{array}$ & $\begin{array}{l}84(40.0) \\
126(60.0)\end{array}$ & $0.000 * *$ \\
\hline \multicolumn{4}{|l|}{ Night duties per week } \\
\hline None & $25(11.9)$ & $41(19.5)$ & \multirow[b]{2}{*}{$0.009 * *$} \\
\hline $\begin{array}{l}1-2 \\
\geq 3\end{array}$ & $\begin{array}{l}125(59.5) \\
60(28.6)\end{array}$ & $\begin{array}{l}132(62.9) \\
37(17.6)\end{array}$ & \\
\hline
\end{tabular}

${ }^{\#}$ Un-married including single, divorced, and widower

* Statistically significant $(p<0.05)$. ** Highly statistically significant $(p<0.01)$

high stress level in ZFH Group which was $75.2 \%$ versus $60.5 \%$ in ZGH Group; especially in subscales of workload, dealing with the death and dying, inadequate emotional preparation, problems relating to supervisors, and uncertainty concerning treatment, patients, and their families (Table 2). Need to employ strict biosecurity measures, personal demands and fears and stigma were significantly higher specific COVID-19-associated stressors among ZFH Group, while exposure to infection risk was significantly higher stressors among ZGH Group. Also, the percent of participants who reported high specific COVID-19-associated stress level in ZFH Group was $71.1 \%$ versus $58.1 \%$ in $\mathrm{ZGH}$ Group with statistically significant difference (Table 2 and Supplementary Table 1).

Job Satisfaction with work conditions seemed significantly lower among ZFH Group $(2.89 \pm 0.81)$ than ZGH Group (3.04 \pm 0.57$)$, especially aspects of control and responsibility, scheduling, interaction, extrinsic reward, and family and work 
Table 2 The Expanded Nursing Stress Scale (ENSS), specific COVID-19-associated stressors (SCAS), and the McCloskey/Mueller Satisfaction Scale (MMSS) among both studied groups

\begin{tabular}{|c|c|c|c|c|}
\hline Scales & & $\begin{array}{l}\text { ZFH Group } \\
N=210\end{array}$ & $\begin{array}{l}\text { ZGH Group } \\
N=210\end{array}$ & $p$ value \\
\hline \multirow[t]{15}{*}{ Expanded Nursing Stress Scale } & ENSS subscales: & Mean \pm SD & Mean $\pm \mathrm{SD}$ & \\
\hline & 1. Dealing with the death and dying (DD) & $24.85 \pm 3.24$ & $18.45 \pm 2.63$ & $<0.0001 * *$ \\
\hline & 2. Conflict with physicians $(\mathrm{CP})$ & $17.65 \pm 6.54$ & $16.33 \pm 5.69$ & 0.097 \\
\hline & 3. Inadequate emotional preparation (IE) & $9.35 \pm 3.54$ & $7.55 \pm 2.39$ & $<0.0001 * *$ \\
\hline & 4. Problems relating to peers $(\mathrm{PP})$ & $20.34 \pm 6.37$ & $18.65 \pm 5.50$ & $0.029 *$ \\
\hline & 5. Problems relating to supervisors (PS) & $25.89 \pm 6.54$ & $18.23 \pm 4.26$ & $<0.0001 * *$ \\
\hline & 6. Workload (WL) & $31.67 \pm 7.31$ & $24.76 \pm 5.41$ & $<0.0001 * *$ \\
\hline & 7. Uncertainty concerning treatment (UT) & $28.24 \pm 8.01$ & $22.87 \pm 6.32$ & $<0.0001 * *$ \\
\hline & 8. Patients and their families $(\mathrm{PF})$ & $25.12 \pm 3.38$ & $19.76 \pm 3.17$ & $<0.0001 * *$ \\
\hline & 9. Discrimination (D) & $10.44 \pm 3.12$ & $10.98 \pm 2.83$ & 0.064 \\
\hline & ENSS (Total score) & $193.55 \pm 44.94$ & $157.58 \pm 39.97$ & $<0.0001 * *$ \\
\hline & Total nursing stress level & n. $(\%)$ & n. $(\%)$ & \\
\hline & Low & $22(10.5)$ & $33(15.7)$ & \\
\hline & Moderate & $30(14.3)$ & $50(23.8)$ & $0.005 * *$ \\
\hline & High & $158(75.2)$ & $127(60.5)$ & \\
\hline \multirow[t]{10}{*}{ Specific COVID-19-associated stress } & SCAS Subscales: & Mean \pm SD & Mean \pm SD & \\
\hline & 1. Need to employ strict biosecurity measures & $16.99 \pm 1.43$ & $9.75 \pm 1.02$ & $<0.001 *$ \\
\hline & 2. Exposure to infection risk & $22.68 \pm 1.85$ & $23.96 \pm 1.93$ & $<0.001 *$ \\
\hline & 3. Personal demands and fears & $27.79 \pm 2.07$ & $24.96 \pm 1.93$ & $<0.001 *$ \\
\hline & 4. Stigma & $7.91 \pm 1.42$ & $6.62 \pm 1.12$ & $<0.001 *$ \\
\hline & SCAS (Total score) & $75.37 \pm 5.09$ & $65.29 \pm 4.42$ & $<0.001 *$ \\
\hline & Total SCAS Level & n. $(\%)$ & n. $(\%)$ & \\
\hline & Low & $25(11.9)$ & $33(15.7)$ & \\
\hline & Moderate & $36(17.1)$ & $55(26.2)$ & $0.021 *$ \\
\hline & High & $149(71.0)$ & $122(58.1)$ & \\
\hline \multirow[t]{14}{*}{ McCloskey/Mueller Satisfaction Scale } & MMSS Subscales: & Mean \pm SD & Mean $\pm \mathrm{SD}$ & \\
\hline & 1. Satisfaction from extrinsic reward (ER) & $2.85 \pm 0.54$ & $3.44 \pm 0.68$ & $<0.0001 * *$ \\
\hline & 2. Satisfaction from scheduling (S) & $2.65 \pm 0.51$ & $4.03 \pm 0.64$ & $<0.0001 * *$ \\
\hline & 3. Satisfaction from family and work balance (FB) & $3.34 \pm 0.67$ & $3.71 \pm 0.63$ & $<0.0001 * *$ \\
\hline & 4. Satisfaction from coworkers (CW) & $3.05 \pm 0.79$ & $3.19 \pm 0.89$ & 0.089 \\
\hline & 5. Satisfaction from interaction (I) & $2.29 \pm 0.64$ & $3.16 \pm 0.58$ & $<0.0001 * *$ \\
\hline & 6. Satisfaction from professional opportunity (PO) & $3.87 \pm 1.08$ & $4.02 \pm 0.91$ & 0.125 \\
\hline & 7. Satisfaction from praise and recognition (PR) & $3.39 \pm 0.64$ & $3.78 \pm 0.58$ & $0.027 *$ \\
\hline & 8. Satisfaction from control and responsibility (CR) & $2.95 \pm 0.63$ & $4.01 \pm 1.08$ & $<0.0001 * *$ \\
\hline & MMSS (total scale) & $2.89 \pm 0.81$ & $3.04 \pm 0.57$ & $0.029 *$ \\
\hline & Total job satisfaction Level & $n(\%)$ & $n(\%)$ & \\
\hline & Low & $107(51.0)$ & 88 (41.9) & \\
\hline & Moderate & $61(29.0)$ & $58(27.6)$ & $0.039^{*}$ \\
\hline & High & $42(20.0)$ & $64(30.5)$ & \\
\hline
\end{tabular}

* Statistically significant $(\mathrm{p}<0.05)$.** Highly statistically significant $(\mathrm{p}<0.01)$

balance $(p<0.01)$ with the percent of participants who reported that low satisfaction level in ZFH Group was $51.0 \%$ versus $41.9 \%$ in ZGH Group (Table 2).

Two Pareto charts were drawn to rank work-related stressors during COVID-19 pandemic that were identified as the most important factors causing about $80 \%$ of occupational stress scores, one for nurses of ZFH (Fig. 1) and the other for nurses of ZGH (Fig. 2). According to the Pareto rule, the first five stressors, (5 out of 13 studied stressors) i.e., almost $38 \%$ of the studied factors, were responsible of $80 \%$ of 
Fig. 1 Pareto chart of work related stressors during COVID19 pandemic among nurses of ZFH Group

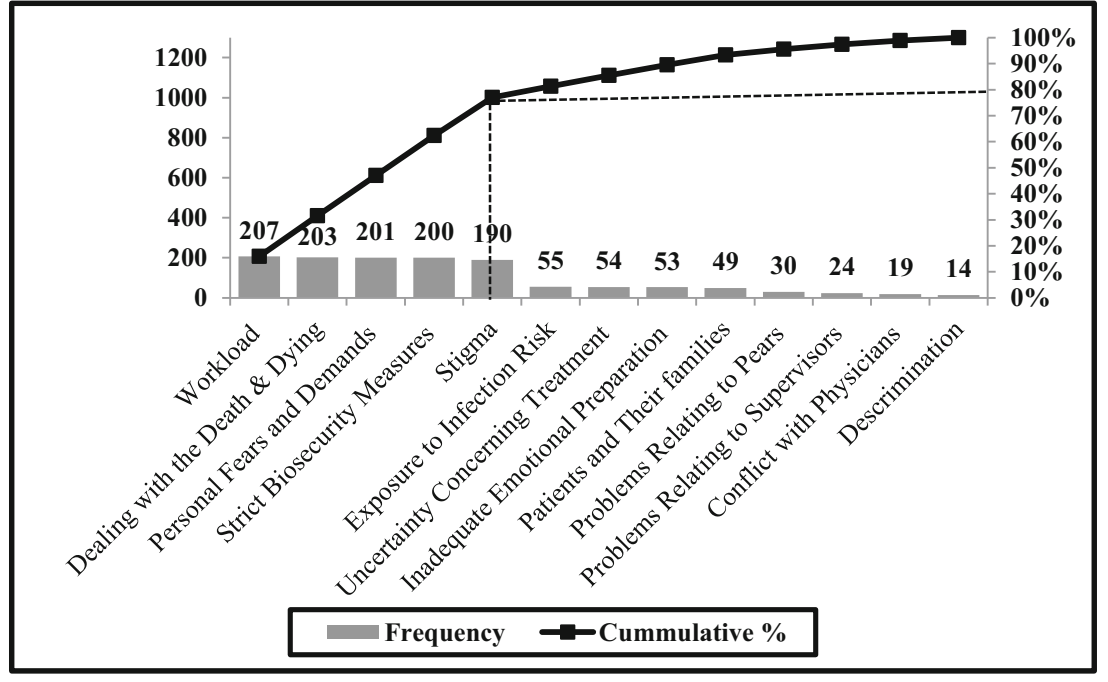

occupational stress among nurses of ZFH, while the first four stressors (4 out of 13 studied stressors), i.e., almost $30 \%$ the studied factors, were responsible of $80 \%$ of the problem in their counterparts in ZGH. The identified factors of occupational stress among nurses of ZFH in order were workload (98.6\%), dealing with death and dying (96.7\%), personal fears and demands (95.7\%), employing strict biosecurity measures (95.2\%), and stigma (90.5\%), while the identified factors of occupational stress among nurses of ZGH in order were fear of exposure to infection (97.6\%), dealing with death and dying $(95.2 \%)$, personal fears and demands (91.4\%), and workload (51.4\%).

Regarding nurses' ratings of their intent to leave, the study revealed that only $4.8 \%$ of nurses in ZFH Group definitely had no intent to leave their present job, while about $24.8 \%$ intended to leave the field of nursing (Fig. 3).

Regarding the relationship between socio-demographic and occupational characteristics of the studied nurses and the studied outcomes, there were statistically significant associations between both age and work hours per week and high scores of all the studied outcomes (Table 3). Accordingly, Binary logistic regression analysis was conducted. Hospital type (ZFH) and work hours/week ( $>40 \mathrm{~h}$ ) were the significant predictors for all the studied outcomes, while night duties/ week $(\geq 3)$ was a predictor for ENSS, specific COVID-19associated stressors, and intent to leave (Table 4).

\section{Discussion}

Nurses in general are exposed to various stressors from physical, psychological, and social working environments which are markedly increased among the front line nurses working in COVID-19 triage hospitals. The most significant stressors for those nurses in this study are related to their physical working environment, i.e., workload (overtime work, frequent night
Fig. 2 Pareto chart of work related stressors during COVID19 pandemic among nurses of ZGH Group. Significance at $* p<$ $0.05, * * p<0.01$

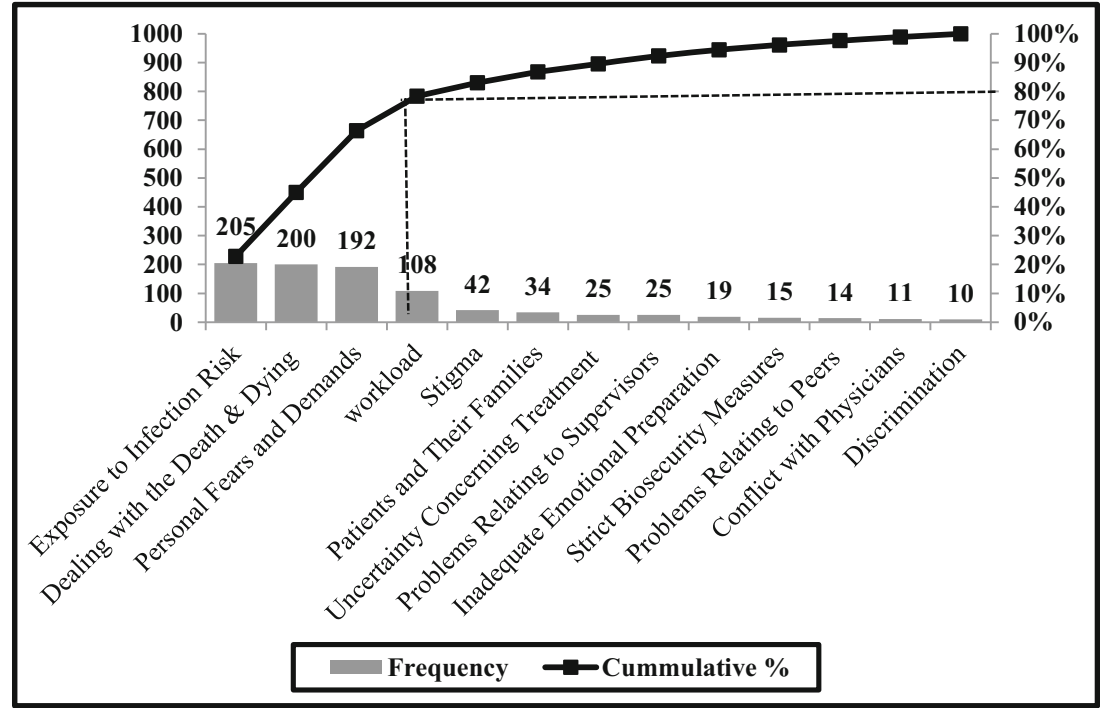


Fig. 3 Nurses' ratings of their intent to leave among both studied groups

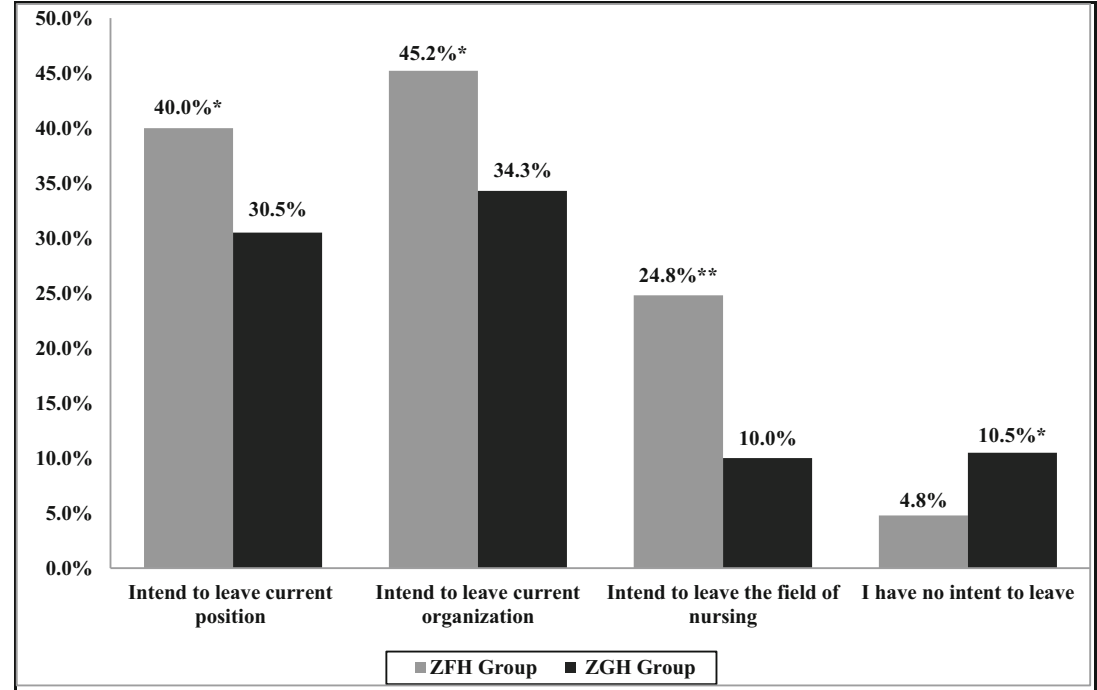

shifts, unsuitable work/rest regimens, and work under pressure to have tasks done in a very short time). This workload resulted from the current isolation policy which calls for reduced outpatient workload in all hospitals except COVID triage and isolation hospitals. This is consistent with Mo et al. (2020) who reported that the unfolding emergency caused by

Table 3 Relationship between socio-demographic and occupational characteristics of the studied groups and high scores of Expanded Nursing Stress Scale (ENSS), specific COVID-19-associated stressors (SCAS), the McCloskey/Mueller Satisfaction Scale (MMSS), and intent to leave

\begin{tabular}{|c|c|c|c|c|c|c|c|c|c|c|c|c|}
\hline \multirow[t]{2}{*}{ Factors } & \multicolumn{2}{|l|}{ High ENSS } & \multirow[t]{2}{*}{$p$} & \multicolumn{2}{|l|}{ High SCAS } & \multirow[t]{2}{*}{$p$} & \multicolumn{2}{|c|}{ High MMSS } & \multirow[t]{2}{*}{$p$} & \multicolumn{2}{|c|}{ Intent to leave } & \multirow[t]{2}{*}{$p$} \\
\hline & $\begin{array}{l}\mathrm{ZFH} \\
(n=158)\end{array}$ & $\begin{array}{l}\mathrm{ZGH} \\
(n=127)\end{array}$ & & $\begin{array}{l}\mathrm{ZFH} \\
(n=149)\end{array}$ & $\begin{array}{l}\mathrm{ZGH} \\
(n=122)\end{array}$ & & $\begin{array}{l}\mathrm{ZFH} \\
(n=42)\end{array}$ & $\begin{array}{l}\mathrm{ZGH} \\
(n=64)\end{array}$ & & $\begin{array}{l}\mathrm{ZFH} \\
(n=209)\end{array}$ & $\begin{array}{l}\mathrm{ZGH} \\
(n=188)\end{array}$ & \\
\hline \multicolumn{13}{|l|}{ Age (years) } \\
\hline $\begin{array}{l}20-39 \\
40-59\end{array}$ & $\begin{array}{r}100(63.3) \\
58(36.7)\end{array}$ & $\begin{array}{l}63(49.6) \\
64(50.4)\end{array}$ & $0.020 *$ & $\begin{array}{l}89(59.7) \\
60(40.3)\end{array}$ & $\begin{array}{l}45(36.9) \\
77(63.1)\end{array}$ & $0.000 * *$ & $\begin{array}{l}27(64.3) \\
15(35.7)\end{array}$ & $\begin{array}{l}30(46.9) \\
34(53.1)\end{array}$ & 0.079 & $\begin{array}{r}126(60.3) \\
83(39.7)\end{array}$ & $\begin{array}{r}84(44.7) \\
104(55.3)\end{array}$ & $0.002 * *$ \\
\hline \multicolumn{13}{|l|}{ Gender } \\
\hline $\begin{array}{l}\text { Male } \\
\text { Female }\end{array}$ & $\begin{array}{r}20(12.7) \\
138(87.3)\end{array}$ & $\begin{array}{l}31(24.4) \\
96(75.6)\end{array}$ & $0.010 *$ & $\begin{array}{r}22(14.8) \\
127(85.2)\end{array}$ & $\begin{array}{l}25(20.5) \\
97(79.5)\end{array}$ & 0.215 & $\begin{array}{r}5(11.9) \\
37(88.1)\end{array}$ & $\begin{array}{l}12(18.8) \\
52(81.2)\end{array}$ & 0.348 & $\begin{array}{r}31(14.8) \\
178(85.2)\end{array}$ & $\begin{array}{r}38(20.2) \\
150(79.8)\end{array}$ & 0.158 \\
\hline \multicolumn{13}{|l|}{ Marital status } \\
\hline $\begin{array}{l}\text { Un-married }{ }^{\#} \\
\text { Married } \\
\text { Education: }\end{array}$ & $\begin{array}{c}89(56.3) \\
69(43.7)\end{array}$ & $\begin{array}{l}45(35.4) \\
82(64.6)\end{array}$ & $0.000 * *$ & $\begin{array}{l}84(56.4) \\
65(43.6)\end{array}$ & $\begin{array}{c}58(47.5) \\
64(52.5)\end{array}$ & 0.147 & $\begin{array}{l}30(71.4) \\
12(28.6)\end{array}$ & $\begin{array}{l}44(68.8) \\
20(31.2)\end{array}$ & 0.769 & $\begin{array}{l}125(59.8) \\
84(40.2)\end{array}$ & $\begin{array}{c}90(47.9) \\
98(52.1)\end{array}$ & $0.017 *$ \\
\hline $\begin{array}{l}\text { Nursing } \\
\text { school or } \\
\text { institute }\end{array}$ & $108(68.4)$ & $75(59.1)$ & 0.104 & $97(65.1)$ & $71(58.2)$ & 0.244 & $28(66.7)$ & $35(54.7)$ & 0.219 & $136(65.1)$ & $115(61.2)$ & 0.421 \\
\hline $\begin{array}{c}\text { Faculty of } \\
\text { nursing }\end{array}$ & $50(31.6)$ & $52(40.9)$ & & $52(34.9)$ & $51(41.8)$ & & $14(33.3)$ & $29(45.3)$ & & $73(34.9)$ & $73(38.8)$ & \\
\hline \multicolumn{13}{|c|}{ Years of experience } \\
\hline $\begin{array}{l}\leq 10 \text { years } \\
>10 \text { years }\end{array}$ & $\begin{array}{r}125(79.1) \\
33(20.9)\end{array}$ & $\begin{array}{l}92(72.4) \\
35(27.6)\end{array}$ & 0.189 & $\begin{array}{r}118(79.2) \\
31(20.8)\end{array}$ & $\begin{array}{l}87(71.3) \\
35(28.7)\end{array}$ & 0.133 & $\begin{array}{r}33(78.6) \\
9(21.4)\end{array}$ & $\begin{array}{l}44(68.8) \\
20(31.2)\end{array}$ & 0.267 & $\begin{array}{r}162(77.5) \\
47(22.5)\end{array}$ & $\begin{array}{r}129(68.6) \\
59(31.4)\end{array}$ & $0.045 *$ \\
\hline \multicolumn{13}{|c|}{ Work hours/week } \\
\hline $\begin{array}{l}40 \mathrm{~h} \\
>40-60 \mathrm{~h}\end{array}$ & $\begin{array}{c}13(8.2) \\
145(91.8)\end{array}$ & $\begin{array}{l}31(24.4) \\
96(75.6)\end{array}$ & $0.000 * *$ & $\begin{array}{c}12(8.1) \\
137(91.1)\end{array}$ & $\begin{array}{l}55(45.1) \\
67(54.9)\end{array}$ & $0.000 * *$ & $\begin{array}{c}3(7.1) \\
39(92.9)\end{array}$ & $\begin{array}{l}28(43.8) \\
36(56.2)\end{array}$ & $0.000 * *$ & $\begin{array}{r}22(10.5) \\
187(89.5)\end{array}$ & $\begin{array}{r}72(38.3) \\
116(61.7)\end{array}$ & $0.000 * *$ \\
\hline \multicolumn{13}{|c|}{ Night duties/week } \\
\hline $\begin{array}{l}<3 \\
\geq 3\end{array}$ & $\begin{array}{r}108(68.4) \\
50(31.6)\end{array}$ & $\begin{array}{r}100(78.7) \\
27(21.3)\end{array}$ & 0.050 & $\begin{array}{r}102(68.5) \\
47(31.5)\end{array}$ & $\begin{array}{r}105(86.1) \\
17(13.9)\end{array}$ & $0.001 * *$ & $\begin{array}{l}28(66.7) \\
14(33.3)\end{array}$ & $\begin{array}{l}50(78.1) \\
14(21.9)\end{array}$ & 0.191 & $\begin{array}{r}149(71.3) \\
60(28.7)\end{array}$ & $\begin{array}{r}156(83.0) \\
32(17.0)\end{array}$ & $0.006^{* *}$ \\
\hline
\end{tabular}

Expanded Nursing Stress Scale (ENSS), McCloskey/Mueller Satisfaction Scale (MMSS), specific COVID-19-associated stressors (SCAS)

${ }^{\#}$ Un-married including single, divorced, and widower. Significance at $* p<0.05, * * p<0.01$ 
Table 4 Binary logistic regression analysis showing the most important predictors of Expanded Nursing Stress Scale (ENSS), Specific COVID-19associated stressors (SCAS), the McCloskey/Mueller Satisfaction Scale (MMSS), and intent to leave

\begin{tabular}{|c|c|c|c|c|}
\hline Variables & S.E. & Wald & Sig. & Odds ratio $(95 \% \mathrm{CI})$ \\
\hline \multicolumn{5}{|l|}{ High ENSS: } \\
\hline - Age (20-39 years old) & 0.91 & 3.94 & $0.047 *$ & $1.66(1.28-9.78)$ \\
\hline • Gender (female) & 0.85 & 0.64 & 0.43 & $0.52(0.10-2.64)$ \\
\hline - Marital status (un-married) & 1.27 & 0.19 & 0.65 & $0.57(0.05-6.88)$ \\
\hline - Work hours/week (>40 h) & 0.001 & 4.22 & $0.042 *$ & $2.0(1.92-2.11)$ \\
\hline • Night duties/week $(\geq 3)$ & 0.02 & 5.93 & $0.014 *$ & $1.31(1.12-1.68)$ \\
\hline • Type of hospital (ZFH) & 0.01 & 5.21 & $0.007 * *$ & $2.14(2.05-3.22)$ \\
\hline \multicolumn{5}{|l|}{ High SCAS: } \\
\hline - Age (20-39 years old) & 0.09 & 4.15 & $0.031 *$ & $1.38(1.24-2.46)$ \\
\hline - Work hours/week (>40 h) & 0.03 & 4.57 & $0.024 *$ & $1.89(1.51-2.13)$ \\
\hline • Night duties/week $(\geq 3)$ & 0.11 & 3.92 & $0.043^{*}$ & $1.53(1.11-3.59)$ \\
\hline - Type of hospital (ZFH) & 0.33 & 4.54 & $0.022 *$ & $2.32(1.76-4.42)$ \\
\hline \multicolumn{5}{|l|}{ High MMSS: } \\
\hline - Work hours/week (>40 h) & 1.31 & 4.01 & $0.048^{*}$ & $1.85(1.43-5.32)$ \\
\hline • Type of hospital (ZFH) & 0.23 & 5.53 & $0.003 * *$ & $3.25(2.11-6.36)$ \\
\hline \multicolumn{5}{|l|}{ Intent to leave: } \\
\hline - Age (20-39 years old) & 0.05 & 0.45 & 0.52 & $1.03(0.94-1.14)$ \\
\hline • Marital status (un-married) & 0.84 & 2.78 & 0.10 & $4.09(0.78-21.42)$ \\
\hline - Work hours/week (>40 h) & 0.05 & 5.97 & $0.003 * *$ & $2.63(1.64-4.28)$ \\
\hline • Night duties/week $(\geq 3)$ & 0.21 & 3.99 & $0.044 *$ & $1.86(1.28-3.15)$ \\
\hline - Type of hospital (ZFH) & 0.09 & 4.25 & $0.034 *$ & $1.99(1.54-3.57)$ \\
\hline
\end{tabular}

Expanded Nursing Stress Scale (ENSS), McCloskey/Mueller Satisfaction Scale (MMSS), specific COVID-19associated stressors (SCAS) ${ }^{*} p<0.05, * * p<0.01$ the COVID-19, the ever-increasing number of confirmed and suspected cases, and heavy workload are putting nursing services under intense pressure.

Furthermore, other significant stressors for those nurses are linked to their psychological working environment including dealing with death and dying, inadequate emotional preparation, and uncertainty concerning treatment. This could be explained by the following facts: nurses, not a relative, are inevitably the last people a dying COVID-19 patient will see, and this put them under great stress (Neto et al. 2020); the COVID-19 outbreak may cause panic emotions among people, and if nurses are not prepared to deal with these emotions, they will be under great tension (CDC 2020); and COVID-19 is newly emerging disease without well-known management plan so regular updates in management protocols, official recommendations, and policies make the nurses lacking autonomy in making decisions and not knowing what the patient or patient's family ought to be told.

Regarding social working environment stressors for those nurses, an analysis of items relating to the factor "problems with peers" revealed that the impossibility of exchanging experiences and feelings with peers were important occupational stressors and this may be attributed to lack of opportunities because of COVID-19-associated overwhelming workload. Also, analysis of the factor "conflicts with supervisors" revealed that lack of support from direct supervisors and usual blaming for uncontrollable errors were significant stressors which surly increased with COVID-19-associated heavy workload. This is consistent with Ghareeb et al. (2014) who reported that nurses are generally treated as scapegoats by other members of the medical profession. Another significant social factor is "the problem with patients and their families" as patient isolation due to COVID-19 and blocking of hospital visits make the nurses the main link between patients and their families with greater exposure to their abuse and unreasonable demands which put them under intense pressure. This is consistent with Hassan et al. (2020) who reported that dealing with angry/blaming relatives and distressed patients, patients/ relatives' expectations of care that cannot be met were important stressors for all healthcare personnel.

During respiratory illness epidemic additional work-related stressors arise; the chief among them is increased exposure to the risk of infection. All HCWs are exposed to this risk; however, the extent of this risk is not distributed equally. Some specialties, like emergency and infectious diseases, are likely to be at a higher risk than other specialties (Simonds and Sokol 2009). The nurses are particularly vulnerable to this risk because they are often the first to respond to patients and have a high level of occupational stress (Oh et al. 2017). Although the study subjects were nurses working in Fever Hospital and 
subsequently their exposure to risk of infection was higher, their worry about acquiring infection was lower than their counterparts in General Hospital. This could be explained by those nurses who had sufficient skill mix and experience to deal with infectious patients (Needleman et al. 2002). This is consistent with $\mathrm{Wu}$ et al. (2020) who reported that medical professionals who were not specialized in infectious disease experienced greater pressure when facing infected patients.

Another dimension to infection risk exposure is stigmatization where people may consider HCWs a movable source of infection in the community (Fischer et al. 2019), so stigmatization was a significant stressor for nurses of ZFH. On the other hand, although employing strict biosecurity measures is a must to prevent spread of infection to self and others, it was a significant stressor for nurses of ZFH. This is consistent with Loibner et al. (2019) who reported that reduced dexterity due to multiple glove layers, impaired visibility by flexible face shields and back pain related to the respirator of the fully ventilated suit, heat stress, and liquid loss were perceived as strong stressors especially at high working temperature. Other significant COVID-19-associated stressors for nurses in both ZFH and ZGH were the personal fears of being isolated, transmitting the disease to families or friends, the unknown duration of the epidemic, lack of treatment for the disease, news of new cases of COVID-19 reported in TV/newspaper, and predictable shortages of staff, supplies, and adequate protective measures. Similar stressors were seen among HCWs who faced SARS (Lee et al. 2005) and MERSA-COV (Khalid et al. 2016) but with variable degrees of stress.

This study used Pareto analysis which allows data to be summarized and displayed in a way to assist in the prioritization of causes of problems as targets for improvement (Banks et al. 1995). It pointed out that $38 \%$ of the studied factors were responsible of $80 \%$ of occupational stress among nurses of fever hospital, while $30 \%$ of these factors were responsible of $80 \%$ of the problem in their counterparts in general hospital; these are too many factors; it is more than $80 / 20$ rule illustrated by Pareto. The policy makers should put coping strategies for all the reported factors to resolve $80 \%$ of the occupational stress or lower this $80 \%$ to $60 \%$ or $70 \%$ thus decrease number of target factors that could be reformed according to the present resources. The most important stressors among nurses of fever hospital were workload, dealing with death and dying, personal demands and fears, employing strict biosecurity measures, and stigma which should be given a priority to be solved through first; to reduce workload, planning of staff numbers according to nursing intensity is required, but this is not always possible so rational distribution of tasks at work is necessary (Riklikienè et al. 2015). Also, involuntary placement and dispatch of usual ward nurses to front-line areas may be a solution to workload problem, but good training to implement effective infection control procedures and proper isolation measures is paramount important to decrease stress among dispatched nurses as fear of exposure to infection had the highest priority as a source of stress among those nurses according to Pareto analysis. Second, to deal with psychological stressors of dealing with death and dying, psychological consultations should be available to nurses after stressful situations (Makie 2006). Third, to deal with personal fears and demands, providing timely, clear, and updated information to nurses with regard to new handling procedures, patient numbers, available resources, and the like is very important. Fourth, to reduce physical strain of protective equipment, synthesis of these equipment from material not causing physical strain is required or division of work to allow each nurse to get enough rest periods from wearing these equipment is a reasonable alternative. Finally, to reduce stigmatization, a checklist prepared by CDC to help identify and address stigmatization before, during, and after infectious disease outbreaks can be used (Department of Health and Human Services 2007).

This highly stressful work environment had reflected on the overall job satisfaction among nurses of fever hospital which was quite low compared to their counterparts in general hospital. This result is supported by previous studies implying that stress at the individual level affects job satisfaction (Sharma et al. 2014; Riklikienè et al. 2015). As current results showed, the main contributors to job dissatisfaction among nurses of fever hospital were the following: first being dissatisfied with extrinsic rewards of their job, praise, and recognition which reflected their belief that their stressful work was not met by adequate financial and moral compensations; second, being dissatisfied with scheduling, family and work balance, and team interaction which surly affected by COVID19-associated heavy workload. Finally, being dissatisfied with control and responsibility as regular updates in COVID-19associated official recommendations and policies hinders the nurses' abilities in making decisions.

There is a vicious circle between occupational stress and job satisfaction where intense stress leads to job dissatisfaction which in turn increases stress; therefore, nurses tend to consider quitting a job at an institution or even changing profession (Moustaka et al. 2010). This explains why the percent of nurses in fever hospital who tend to leave the current organization or even changing job was more than their counterpart in general hospital. Previous studies during the 2003 SARS outbreak showed that HCWs reported reluctance to work or contemplating resignation (Bai et al. 2004).

Although there were statistically significant differences in age, marital state, and experience between both study groups, only statistically significant association was found between age and high scores of all the studied outcomes and when Binary logistic regression analysis was conducted to exclude age as a confounding factor, hospital type (ZFH) with its related workload factors was the significant predictor for all the studied outcomes. 


\section{Limitation}

This study had some limitations. First, the study did not include all nurses who experienced the outbreak especially those of isolation hospital. Second is the use of the simplistic one item of intent to leave that provided only a general orientation about nurses' intent to leave. Lastly, the study hospitals were sampled conventionally so the results may reflect the conditions in these specific hospitals, which affect generalizability of the findings.

Conclusion and recommendations Nearly all work-related physical, psychological, and social stressors increased among nurses of COVID-19 triage hospitals compared to those working in general hospitals which are not triage or isolation hospitals indicating that COVID-19 pandemic added an extra load on this already stressful job. Workload, dealing with death and dying, personal demands and fears, employing strict biosecurity measures, and stigma represented the high-priority stressors among nurses of triage hospitals responsible for $80 \%$ of occupational stress problem, while exposure to infection risk was the stressor of highest priority among nurses of general hospital. This highly stressful work environment resulted in job dissatisfaction with tendency to leave job in the future. This emphasis adopting strategies to reduce perceived jobrelated stress increases effectively job satisfaction, and decreases turnover intention during these difficult events.

Acknowledgments The authors would like to thank all participants of this study for their great cooperation.

Authors' contributions All authors were responsible for study. All authors contributed to the study conception and design. Material preparation was performed by [Randa M. Said]. Data management was performed by [Dalia A. El-Shafei]. The first draft of the manuscript was written by all authors. All authors read and approved the final manuscript.

Data availability of data and materials The datasets used and /or analyzed during the current study are available from the corresponding author on reasonable request.

\section{Compliance with ethical standards}

Conflict of interest The authors declare that they have no conflict of interest.

Ethical approval The Institutional Review Board (IRB) of the Faculty of Medicine, Zagazig University approved the study protocol (reference no: \#6354). Ethical considerations and confidentiality were respected.

Consent to participate An informed consent was obtained from all participants of this study. The nurses were told about the aim of the study, and they were informed that the data would be used for scientific purposes only. The nurses were also given the right to refuse or participate in the study.

Consent to publish Not applicable

\section{References}

Bai Y, Lin CC, Lin CY, Chen JY, Chue CM, Chou P (2004) Survey of stress reactions among health care workers involved with the SARS outbreak. Psychiatr Serv 55(9):1055-1057

Banks NJ, Palmer RH, Berwich DM, Plesk P (1995) Variability in clinical systems: applying modern quality control methods to health care. Jt Comm J Qual Improv 21(8):407-419

CDC (2020) Coronavirus Disease 2019 (COVID-19) Daily Life \& Coping. https://www.cdc.gov/coronavirus/2019-ncov/daily-lifecoping/managing-stress-anxiety.html. Accessed 30 Apr 2020

Department of Health and Human Services (2007) Centers for Disease Control and Prevention Checklist: inhibiting and countering stigmatization in crisis and emergency risk communication: pandemic influenza. https:// emergency.cdc.gov/cerc/cerconline/pandemic/ pandemic/transcripts/checklist3.pdf. Accessed 10 May 2020

Fischer LS, Mansergh G, Lynch J, Santibanez S (2019) Addressing disease-related stigma during infectious disease outbreaks. Disaster Med Public Health Prep 13(5-6):989-994

French SE, Lenton R, Walters V, Eyles J (2000) An empirical of an expanded nursing stress scale. Nursing Stress Scale. J Nurs Meas 8(2):161-178

Ghareeb NS, Aboserea MM, Oraby EE (2014) Assessment of work stress and organizational commitment among female nurses at Zagazig University Hospitals, Sharkia Governorate, Egypt. Middle East J Appl Sci 4(1):86-95

Hassan NM, Abu-Elenin MM, Elsallamy RM, Kabbash IA (2020) Job stress among resident physicians in Tanta University Hospitals, Egypt. Environ Sci Pollut Res 27:37557-37564. https://doi.org/10. 1007/s11356-020-08271-9

Hoboubi N, Choobineh A, Ghanavati FK, Keshavarzi S, Hosseini AA (2017) The impact of job stress and job satisfaction on workforce productivity in an Iranian petrochemical industry. Saf Health Work 8(1):67-71. https://doi.org/10.1016/j.shaw.2016.07.002

Jun J, Tucker S, Melnyk BM (2020) Clinician mental health and wellbeing during global healthcare crises: evidence learned from prior epidemics for COVID-19 pandemic. Worldviews Evid-Based Nurs 17(3):182-184. https://doi.org/10.1111/wvn.12439

Kabbash IA, El-Sallamy RM, Abdo SAE, Atalla AO (2020) Job satisfaction among physicians in secondary and tertiary medical care levels. Environ Sci Pollut Res 27:37565-37571. https://doi.org/10.1007/ s11356-020-08506-9

Kamal AM, Nagy NE, Bakr IM, Abdel Aal M (2005) Work related stress among staff nurses in Ain Shams University Hospitals- CairoEgypt. Curr Psychiatr Ther 12(1):107-121

Khalid I, Khalid TJ, Qabajah MR, Barnard AG, Qushmaq IA (2016) Healthcare workers emotions, perceived stressors and coping strategies during a MERS-CoV outbreak. Clin Med Res 14(1):7-14

Lagerlund M, Sharp L, Lindqvist R, Runesdotter S, Tishelman C (2015) Intention to leave the workplace among nurses working with cancer patients in acute care hospitals in Sweden. Eur J Oncol Nurs 19(6): 629-637. https://doi.org/10.1016/j.ejon.2015.03.011

Lee SH, Juang YY, Su YJ, Lee HL, Lin YH, Chao CC (2005) Facing SARS: psychological impacts on SARS team nurses and psychiatric services in a Taiwan general hospital. Gen Hosp Psychiatry 27:352358

Lo WY, Chien LY, Hwang FM, Huang N, Chiou ST (2018) From job stress to intention to leave among hospital nurses: a structural equation modelling approach. J Adv Nurs 74:677-688. https://doi.org/ 10.1111/jan.13481

Loibner M, Hagauer S, Schwantzer G, Berghold A, Zatloukal K (2019) Limiting factors for wearing personal protective equipment (PPE) in a health care environment evaluated in a randomised study. PloS one 14(1):e0210775. https://doi.org/10.1371/journal.pone.0210775 
Makie V (2006) Stress and coping strategies amongst registered nurses working in a South African tertiary hospital. Magister curationis. http://etd.uwc.ac.za/xmlui/bitstream/handle/11394/1983/Makie MCUR_2006.pdf? sequence=1. Accessed 29 Apr 2020

Ministry of health and population (2020) Suspected COVID-19 cases management in General Hospitals and Triage Hospitals. Coronavirus disease 2019 (COVID-19) update weekly report (1723 April 2020). Infectious Diseases Unit - Endemic Medicine Department - Cairo University

Mo Y, Deng L, Zhang L, Lang Q, Liao C, Wang N, Qin M, Huang H (2020) Work stress among Chinese nurses to support Wuhan for fighting against the COVID-19 epidemic. J Nurs Manag Accepted Author Manuscript 28:1002-1009. https://doi.org/10.1111/jonm. 13014

Moustaka E, Antoniadou F, Maliarou M, Zantzos I, Kyriaki K, Constantinidis $\mathrm{T}$ (2010) Research in occupational stress among nursing staff - a comparative study in capital and regional hospitals. Hellenic J Nurs Sci 3:79-84

Mueller CW, McCloskey JC (1990) Nurses' job satisfaction: a proposed measure. Nurs Res 39:113-117

Needleman J, Buerhaus P, Mattke S, Stewart M, Zelevinsky K (2002) Nurse-staffing levels and the quality of care in hospitals. N Engl J Med 346:1715-1722

Neto M, Almeida HG, Esmeraldo JD, Nobre CB, Pinheiro WR, de Oliveira C, Sousa I, Lima O, Lima N, Moreira MM, Lima C, Júnior JG, da Silva C (2020) When health professionals look death in the eye: the mental health of professionals who deal daily with the 2019 coronavirus outbreak. Psychiatry Res 288:112972. Advance online publication. https://doi.org/10.1016/j.psychres.2020.112972

Oh N, Hong N, Ryu DH, Bae SG, Kam S, Kim K (2017) Exploring nursing intention, stress, and professionalism in response to infectious disease emergencies: the experience of local public hospital nurses during the 2015 MERS outbreak in South Korea. Asian Nurs Res 11:230e 236

Riklikienė O, Krušinskaitė D, Gatautis R, Bagdonaitė Ž (2015) Nurses' work-related stress, job satisfaction, and intent to leave: a survey in primary health care centers. NERP 5(1):11-20

Semachew A, Belachew T, Tesfaye T, Adinew YM (2017) Predictors of job satisfaction among nurses working in Ethiopian public hospitals, 2014: institution-based cross-sectional study. Hum Resour Health 15(1):31. https://doi.org/10.1186/s12960-017-0204-5

Sharma P, Davey A, Davey S, Shukla A, Shrivastava K, Bansal R (2014) Occupational stress among staff nurses: Controlling the risk to health. Indian Journal of Occupational and Environmental Medicine 18(2):52-56. https://doi.org/10.4103/0019-5278.146890

Simonds AK, Sokol DK (2009) Lives on the line? Ethics and practicalities of duty of care in pandemics and disasters. Eur Respir J 34:303309

Tourangeau AE, Hall LM, Doran DM, Petch T (2006) Measurement of nurse job satisfaction using the McCloskey/Mueller Satisfaction Scale. Nurs Res 55:128-136

US National Center for Posttraumatic Stress Disorder (2020) Managing healthcare workers' stress associated with the COVID-19 virus outbreak. U.S. Department for Veterans Affairs. www.ptsd.va.gov. Accessed 21 Mar 2020

Wu Y, Wang J, Luo C, Hu S, Lin X, Anderson AE, Bruera E, Yang X, Wei S, Qian Y (2020) A comparison of burnout frequency among oncology physicians and nurses working on the front lines and usual wards during the COVID-19 epidemic in Wuhan, China. J Pain Symptom Manag S0885-3924(20)30205-0. Advance online publication. https://doi.org/10.1016/j.jpainsymman.2020.04.008

Publisher's note Springer Nature remains neutral with regard to jurisdictional claims in published maps and institutional affiliations. 